\title{
Respuestas a la incertidumbre de los trabajadores del textil-confección valenciano
}

\author{
Sandra Obiol Francés \\ Departamento de Sociología y Antropología Social, Universidad de València \\ Grupo Interuniversitario Copolis. Bienestar, Comunidad y Control Social \\ sandra.obiol@uv.es
}

Recibido: 29-01-2013

Aceptado: 11-04-2013

Resumen: La gestión política y empresarial de la liberalización del comercio de sus productos abrió a mediados de la década del 2000 una importante crisis en el sector del textil-confección. Una crisis especialmente aguda en las comarcas valencianas de l’Alcoià, el Comtat y la Vall d'Albaida donde no sólo la economía sino también el imaginario social de sus habitantes se ha construido tradicionalmente sobre este sector. Esta situación sirvió para la investigación que origina el artículo como metáfora de la percepción de la incertidumbre, entendida ésta como la falta de códigos válidos para dotar de significado los hechos que se viven en la cotidianeidad y en consecuencia la incapacidad para planificar a largo plazo tanto a nivel laboral como vital.

El principal objetivo del artículo ha sido exponer las conclusiones de la investigación realizada sobre las respuestas de los trabajadores del textil y confección de las comarcas citadas ante la incertidumbre. Más en concreto, el propósito era conocer a través del análisis de sus discursos de qué manera los trabajadores del textil-confección encaraban la falta de certeza. La respuesta mayoritaria ha sido el rechazo a todo posible cambio que genere duda y la defensa ante ella así como su minimización haciendo uso de los escasos instrumentos que la clase trabajadora tiene a su alcance: la privatización de sus intereses, la limitación de las expectativas de consumo y de vida, y el intento de sumergir toda su vida en una mínima rutina que les permita la planificación que la incertidumbre les sustrae.

Palabras claves: clave: incertidumbre, estrategias, bienestar, sector textil-confección 


\title{
Answers to the uncertainty from the workers in the Valencian textile and clothing sector
}

\begin{abstract}
The political and business management of trade liberalization process in textile and clothing sector opened a major crisis in the mid-2000s. This crisis was especially acute in Valencian regions of Alcoià, Comtat and Vall d'Albaida where not only the economy but also the social imaginary of its inhabitants have been built over this sector traditionally. For the research whose originates this article, this situation served as a metaphor for the perception of uncertainty, understood as the lack of valid codes to make sense of the events that are experienced in everyday life and consequently, the inability to plan long-term employment as both life.

The main objective of this article has been to set out the conclusions of the research on the responses of workers facing with the uncertainty in the textile and clothing industry regions previously mentioned. More specifically, the purpose was to find out about how the textile and clothing workers faced with the uncertainty through the analysis of their speeches. The majority response has been the rejection of any possible change that causes doubt, also the defense against it, as well as its minimization using the few tools that has the working-class at its disposal: the privatization of their interests, the limitation of their expectations about consumption and living in general, and the attempt to immerse oneself in a routine that allows a minimal planning which the uncertainty takes them.
\end{abstract}

Key words: Uncertainty, strategies, welfare, textile and clothing sector

\section{Referencia normalizada}

Obiol Francés, S. (2013). "Respuestas a la incertidumbre de los trabajadores del textil-confección valenciano”. Política y Sociedad, Vol.50 Núm. 3 1009-1036

Sumario: Introducción. 1.Respuestas estratégicas al riesgo. 2.Una certeza ambivalente. 3.Los trabajadores del textil-confección ante la incertidumbre 4.La incertidumbre como elemento de dominación.

Bibliografía

\section{Introducción}

Firmado en 1995 el Agreement on Textiles and Clothing de la Organización Mundial del Comercio suponía la progresiva liberalización del sector del textil y la confección. A lo largo de un período de diez años se debían ir eliminando las cuotas proteccionistas que habían caracterizado el sector durante décadas para ir abriendo los mercados a productos de terceros países. El retraso en la aplicación del acuerdo ${ }^{1}$ junto la convergencia con la crisis económica global que aún padecemos, multiplicó

${ }^{1}$ A finales de 2004 de las 218 restricciones establecidas en la Unión Europea todavía se aplicaban 210 (Sebastià, 2005). 
sus efectos -económicos, laborales, sociales- especialmente en una zona como en la que centro el análisis: las comarcas valencianas de l'Alcoià, El Comtat y la Vall d’Albaida, cuya economía, así como su imaginario social, se ha fundamentado tradicionalmente en el sector citado.

En este territorio la gestión política y empresarial del proceso de liberalización tuvo, entre otras consecuencias, el cierre de decenas de fábricas y talleres, la reducción del volumen de trabajadores -una reducción de difícil valoración dada la importancia en la zona de la economía informal - así como el cambio en las condiciones de trabajo de centenares de personas, pero, sobre todo, supuso la presencia constante de la crisis en los medios de comunicación locales un hecho que hacía imposible escapar de la constatación de estar inmersos en una situación crítica. Y llovía sobre mojado.

Los rasgos definitorios del sector del textil-confección en las comarcas analizadas evidencian una precariedad previa a la crisis que ésta viene a agravar, entendiendo precariedad como la incapacidad de sus trabajadores para poder planificar su vida respecto a su situación laboral (Cano, 2000). Se trata de un sector con empresas de tamaño reducido ${ }^{2}$ y de carácter familiar, lo que favorece la individualización de las relaciones laborales; un sector de largas jornadas y bajos salarios, con una significativa incidencia de la informalidad y de la siniestralidad laboral ${ }^{3}$. Es también un sector profundamente irregular, que ha vivido numerosas crisis y que combina periodos de un ritmo de trabajo frenético con otros de, prácticamente, inactividad. De hecho, la coyuntura económica surgida de la liberalización podría haber sido una más de las muchas crisis que ha vivido el sector si no significara la erosión de la que ha sido durante años su principal baza: el bajo coste de la mano de obra. Paradójicamente las, ligeras, mejoras en derechos laborales y sociales que los trabajadores han conseguido en los últimos años suponen el debilitamiento de su posición en un mercado global donde conseguir el máximo beneficio económico, de unos pocos, se instituye como criterio rector.

Por otro lado, esta crisis se da en un país donde el bienestar de las personas depende de la solidez de los vínculos familiares y de parentesco. Son las familias, esencialmente las mujeres, las que aportan a los individuos cuidado, apoyo, capital

${ }^{2}$ En 2008 un 52\% del total de empresas del sector valenciano se podrían considerar microempreses, con menos de 10 asalariados (elaboración propia a partir del Directorio central de empresas, INE).

${ }^{3}$ Con episodios funestos como es el caso del síndrome Ardystil - cuyo nombre se toma de la empresa contestana donde se dio con mayor virulencia- se hizo público en el año 1992 y fue provocado por un mal uso de productos químicos utilizados en las aerografías de estampado textil proporcionados por la multinacional Bayer en combinación con unas pésimas condiciones laborales. Causó la muerte de seis trabajadores (de los cuales cinco mujeres) y más de 50 enfermos de fibrosis pulmonar. Un caso que según Vogel (1995) ejemplifica la subordinación del bienestar de la sociedad al beneficio económico a través de la normalización de la precariedad laboral. 
social, bienestar en definitiva (Ferrera, 1995, 1996; Mingione, 2000; Montagut, 2000; Naldini, 2003; Saraceno, 1995; Trifiletti, 1999). No obstante, esta solidez que nutre el bienestar de los países del Sur de Europa, se podría estar erosionando. Las transformaciones ocurridas en el seno del mercado de trabajo, del estado y de la familia, pero sobre todo los profundos cambios que se están sucediendo en la configuración de la identidad individual parecen poner en peligro estos vínculos que hasta ahora proporcionaban bienestar a los ciudadanos de estos territorios.

La situación descrita me sirvió en la investigación en la que se basa este artículo ${ }^{4}$ para analizar la percepción y respuesta de los trabajadores del textil-confección a la incertidumbre generada por la liberalización comercial del sector a través de los que se han considerado los principales agentes proveedores de bienestar: familia, mercado, estado y, también, esfera relacional. Apoyados en estos pilares los trabajadores del textil-confección dibujan un mosaico de respuestas a la incertidumbre condicionado, es decir, ajustado, por su posición de clase. En el presente artículo no pretendo exponer este entramado de estrategias de respuesta a la incertidumbre, aunque necesariamente esté presente, si no el urdimbre que las sustenta, los fundamentos con los que cuentan, según sus palabras, los trabajadores entrevistados para afrontar la incertidumbre y los efectos que ésta tiene sobre su manera de moverse por el mundo. El artículo se divide en cuatro grandes apartados:

- En primer lugar apunto brevemente las principales líneas de reflexión teórica que sostuvieron la investigación matriz del presente artículo y que proceden de la convergencia de tres grandes debates: el nuevo concepto de riesgo procedente del actual análisis de la sociedad occidental; las estrategias a través de las cuales los individuos buscan bienestar y la noción de régimen de bienestar del Sur de Europa.

- En segundo lugar, apunto a la ambivalencia en términos de incertidumbre de los considerados agentes de bienestar. Las transformaciones que están experimentado mercado, familia y estado generan dudas acerca de su capacidad de provisión de bienestar, de certeza.

- A continuación, describo las principales posiciones que los trabajadores del sector del textil-confección en las comarcas de l'Alcoià, el Comtat y la Vall d'Albaida toman frente la incertidumbre.

- El artículo acaba con unas conclusiones en las que se apunta a la incertidumbre como un elemento de dominación de la clase trabajadora.

${ }^{4}$ Este artículo muestra parte de los resultados obtenidos en mi tesis doctoral "Teixir certeses. Percepcions i respostes a la incertesa dels treballadors del tèxtil-confecció a l’Alcoià, el Comtat i la Vall d’Albaida” Julio 2010, Universidad Autònoma de Barcelona, dirigida por la Dra. Elisabet Almeda. 


\section{Respuestas estratégicas al riesgo}

El estudio del riesgo ${ }^{5}$ y el deseo de identificarlo, medirlo y preverlo ha estado presente en la reflexión científica durante décadas; hoy el debate, al menos en Sociología, ha tomado nuevos bríos ${ }^{6}$. La mirada se centra no tanto en la previsión como en el conocimiento del efecto que la percepción del riesgo puede tener en la construcción de la identidad individual y en las relaciones interpersonales, incluso en sus consecuencias políticas. En este sentido ha sido fundamental la repercusión que han obtenido las reflexiones sobre la sociedad occidental y su relación con el riesgo del sociólogo alemán Ulrich Beck, cuya teorización se encuadra en la relación entre riesgo y los macroprocesos sociales en la modernidad avanzada (Lupton, 1999).

A lo largo de su obra el autor nos plantea el momento en el que vivimos como una transición desde la Primera a la Segunda Modernidad donde el riesgo se convierte en un rasgo central. Dejamos atrás, afirma, una sociedad caracterizada por la plena ocupación, la territorialización en estados-naciones, el Estado de bienestar y unas relaciones de explotación de una naturaleza sumisa. Progresivamente abandonamos una sociedad industrial, simple, lineal y basada en la certeza, en la capacidad de cuantificar y controlar los posibles riesgos y peligros de la cotidianeidad; pasamos, como nos señala Ramos (2006:31) "del riesgo administrado a la incertidumbre desatada”. Las pautas colectivas de vida, progreso y controlabilidad de la Primera Modernidad se verán socavadas por cinco procesos interrelacionados: globalización, individualización, revolución de los géneros, subocupación y riesgos globales (como las crisis ecológicas o el colapso de los mercados financieros), a los cuales,

${ }^{5}$ Según Lupton (1999) en la edad moderna existía una diferenciación entre riesgo e incertidumbre que hoy se ha perdido. Como riesgo se entendería la posibilidad de conocer, o al menos estimar, los hechos a los cuales se hace referencia, mientras que la incertidumbre se refiere a todos aquellos fenómenos que no pueden ser conocidos ni estimados. Adams (1995) reitera esta diferencia dando a entender que en los tiempos modernos había una parte de la realidad que se mantenía en la oscuridad para el sujeto racional. Por otro lado, Ramos (2004, 2006) nos presenta una incertidumbre contenida por el riesgo, tanto en la acepción de inclusión como en la de mantener bajo control; hoy, sin embargo, esta capacidad de contención se ha visto desbordada según el autor.

${ }^{6}$ Son muchos los autores que han tratado de aprehender el significado de los numerosos cambios que se están viviendo en la sociedad occidental desde la década de los 70 en los que el riesgo ocupa un lugar predominante. La crisis económica del petróleo y sus efectos en el trabajo remunerado, en la configuración del Estado de bienestar y también en la vida cotidiana y en las estructuras de sentido de las personas ha supuesto una importante línea de investigación en Ciencias Sociales (Bauman, 2001, 2003, 2005a, 2005b, 2005c, 2006, 2007a, 2007b; Beck, 1996, 1998, 2000, 2002; Beck y Beck-Gernsheim, 2001, 2003, 2008; BeckGernsheim, 2003; Beck, Giddens y Lash, 1994; Castel, 1995, 2003, 2009; Giddens, 1991, 1995, 2000; Luhmann, 1998; Sennett, 2000, 2006; Young, 2007, entre otros). 
sobre todo, es imprescindible responder de manera simultánea (Beck, 2000, 2002). La Segunda Modernidad vendría definida así por las consecuencias sobrevenidas y no deseadas de la primera etapa, por la generalizada percepción de la incertidumbre. Consecuencias que nos desconciertan pues no tenemos suficientes referencias para ordenarlas cognitivamente bajo los parámetros tradicionales y por tanto servir a la acción (Beck y Beck-Gernsheim, 2003). En la actualidad el riesgo ocupa un lugar central en los significados simbólicos y materiales de nuestra vida cotidiana, llegando incluso a sumergir en inseguridad ámbitos que hasta ahora parecían libres de la misma constituyendo el núcleo de nuestras certezas como es el caso de la tecnociencia (Ramos, 2004, 2006). Es la percepción generalizada de la incertidumbre, para unos valiosa y alentadora, para otros profundamente dolorosa, el elemento intrínseco que caracteriza hoy la cultura que compartimos en la sociedad occidental, sin dejar por ello de lado el carácter profundamente cultural de su percepción y aceptabilidad (Douglas y Wildavsky, 1983; Douglas, 1992). Una percepción en la que tiene un papel esencial la transformación de las bases constitutivas de la identidad individual hacia la transitoriedad, la necesidad de decisión ante opciones cada vez más diversas y la asunción individual de la responsabilidad de las decisiones tomadas (Bauman, 2003, 2005, 2006; Beck y Beck-Gernsheim, 2003).

En este estudio, el escenario dibujado por los efectos de la gestión de la liberalización comercial del textil-confección para sus trabajadores sirve de metáfora de este proceso de pérdida de antiguas fuentes de certeza sin conseguir, al menos de momento, ser sustituidas. Por ello, en este contexto y con fines analíticos, considero incertidumbre la ausencia de elementos válidos para interpretar la situación en la que se vive y en consecuencia la incapacidad para planificar a largo plazo tanto a nivel laboral como vital. Mi propósito en la investigación ha sido averiguar qué respuestas dan los trabajadores entrevistados a la percepción de la incertidumbre, qué "estrategias de aseguramiento", según Beck-Gernsheim (2003), llevan adelante. La autora afirma que una de las respuestas a la sensación de riesgo -en su caso hablando de los cambios en las familias- es la estrategia de aseguramiento, es decir, buscar a través de una intensa y extensa planificación la seguridad que se echa en falta. Una estrategia que se ha transformado en norma social básica en la sociedad occidental siendo sancionadas aquellas personas con poco espíritu de previsión y que toman opciones equivocadas según los parámetros culturales dominantes.

A partir de esta idea he intentado conocer cómo los trabajadores del textilconfección gestionan la incidencia de la incertidumbre en su vida cotidiana, cómo combinan los recursos ${ }^{7}$ que tienen a su disposición en un momento en el que asisten a la transformación de la vida que han conocido hasta el momento y cómo en esta combinación influyen variables estructurales, cuestionando de este modo al riesgo

\footnotetext{
${ }^{7}$ Esta combinación de recursos converge con el concepto de capital social (para más información ver Portes, 1998, 2000). Sin embargo mi intención en esta investigación no ha sido analizar la densidad y fortaleza de las redes sino cómo los individuos manejan los recursos que tienen a su alcance.
} 
la capacidad democratizadora que le otorga Beck (2008) y por lo que ha sido criticado por diversos autores (Blossfeld et al. 2005, 2006, 2008a, 2008b; Elliot, 2002; Lupton y Tulloch, 2002; Mythen, 2007; Tulloch y Lupton, 2003).

Este propósito se inspira claramente en el estudio relacional de la sociedad que Bourdieu defiende. A partir de la posición ocupada en el campo - "una red, o una configuración de relaciones objetivas entre posiciones” (con Wacquant 1994:73)- se consigue un habitus, una "subjetividad socializada", producto de nuestra historia social y personal que a la vez contiene una importante vertiente creativa y que otorga los instrumentos para interpretar la vida cotidiana y actuar en consecuencia (Bourdieu y Wacquant, 1994; Bourdieu, 2003). Para los trabajadores en los que centro el estudio las transformaciones que experimentan los cimientos de su cotidianeidad, con el empleo de manera central, invalidan la capacidad interpretativa de los códigos con los que se han socializado, al tiempo que se debilita su posición de campo lo que les genera una aguda sensación de inquietud. ${ }^{8}$

En este sentido considero estrategias "las líneas de acción objetivamente orientadas que los agentes sociales construyen sin parar, en la práctica y prácticamente, y que se definen en la intersección entre el habitus y una coyuntura particular del campo" (Bourdieu y Wacquant, 1994:106). Las estrategias son entendidas aquí como prácticas sociales dirigidas a enfrentarse a la situación que inaugura la liberalización del comercio del sector, enmarcada en un proceso de globalización y cambio económico y social de mayor entidad. El uso del concepto en un momento de cambio es pertinente porque, como nos señala Tobío (2005:139) para el caso de las madres trabajadoras, a pesar de no menospreciar el componente irracional e inconsciente del comportamiento del individuo - en el que también encontraríamos un claro sustrato social- se ha de esperar que en el momento de enfrentarse a nuevos problemas donde no hay respuestas ya ensayadas por otros, la racionalidad e intencionalidad tomen mayor peso.

Ante estos intereses analíticos el concepto de régimen de bienestar emerge por su capacidad explicativa respecto a la mayoría de las estrategias de búsqueda de nuevos apoyos por parte de los trabajadores, o bien la consolidación de antiguos en una coyuntura de notable transformación. Aunque también hemos de considerar su capacidad para crear nuevos riesgos sociales como veremos en el siguiente apartado. Siguiendo a Esping-Andersen (2000:52) -especialmente a las críticas que recibió su propuesta - podemos encontrar tres canales fundamentales de distribución y provisión de bienestar: el estado, la familia, y el mercado. La interrelación entre estas esferas, donde incluyo también la esfera relacional (Adelantado, Noguera y Rambla,

${ }^{8}$ Precisamente, el concepto de estrategia se ha utilizado sobre todo en momentos de transición (como es el poscomunismo o el posfordismo) o en el estudio de las decisiones individuales o familiares en situaciones que se alejan del modelo de vida hegemónico, como puede ser la monoparentalidad (Gardberg, 2000) o la supervivencia en contextos de precariedad económica (Pahl, 1984; Pahl y Wallace, 1985; Smith y Macnicol, 2001). 
2000), dibuja un determinado modelo de bienestar, y al mismo tiempo el bienestar de los individuos procede del modo en que combinan las posibilidades que les ofrecen estos agentes proveedores.

En el caso valenciano, como en el resto del estado español junto a Grecia, Italia y Portugal, nos encontramos inmersos en lo que se ha venido llamando régimen de bienestar sudeuropeo. Este régimen se caracteriza por tener sistemas de protección social elaborados por parte de un estado con débil penetración en la sociedad civil y muy desprestigiado en gran medida por su pasado autoritario, que sigue pautas de clientelismo (Ferrera, 1995, 1996; Mingione, 2000; Montagut, 2000; Saraceno, 1995; Trifiletti, 1999). Pero sobre todo le diferencia del resto de regimenes de bienestar el marcado sesgo familiar de las dinámicas de provisión de bienestar. La familia, en sentido extenso (Naldini, 2003), se ha convertido en estos territorio en la principal red de protección de la población contra los riesgos sociales.

En conclusión, el proceso de transformación de la sociedad occidental con la profunda erosión de los que han sido los cimientos, materiales y simbólicos, de la Primera Modernidad ha constituido en esta investigación la plataforma desde donde observar la gestión de la incertidumbre en el régimen de bienestar sudeuropeo en un caso muy concreto: los efectos sobre sus trabajadores de la liberalización comercial del sector del textil y la confección. El objetivo central del artículo es mostrar la respuesta de estos trabajadores a la incertidumbre que les puede suponer la crisis abierta en su sector enmarcada en un proceso de globalización y de cambio económico y social de mayor alcance. Una crisis que les impide plantearse el futuro, pero también el presente, con los elementos de significado que les han funcionado hasta el momento, circunstancia que les genera -lo dejan claro en sus discursos- un profundo desasosiego.

\section{Una certeza ambivalente}

Mercado, familia y estado son a la vez proveedores de certezas e incertezas, sobre todo en momentos de transformación como el que estamos viviendo en los últimos años.

La liberalización comercial del textil-confección, que sirve como punto de partida de la investigación converge con una situación más amplia de cambios profundos en el mercado de trabajo a raíz de la crisis del petróleo y de la imposición como respuesta de una nueva ortodoxia económica donde la flexibilidad -aplicada de manera unilateral y centrada en la gestión de la fuerza de trabajo- se convierte en solución incuestionable a todos los males. Se transita así desde una "norma social de empleo salarial" o "norma salarial de empleo", a "la norma de empleo flexibilizada” (Prieto, 2002). Estamos pasando de una configuración social, económica, política y cultural construida sobre los cimientos de un puesto de trabajo estandarizado, estable, con un salario regular y, por supuesto, masculino, a otra donde lo que se ha convertido en habitual es la diversidad, la inestabilidad, la precariedad y la incertidumbre, todo ello construido en torno a una pretendida flexibilidad para la 
adaptación a las volátiles necesidades del mercado. La cantidad por encima de la calidad en el empleo y ésta relegada a intereses macroeconómicos como la disminución del déficit público y la inflación (Cano, 2007). Se impone hoy la cultura del nuevo capitalismo, como lo llama Sennett (2006), donde la planificación a largo plazo, la estabilidad y la seguridad han sido defenestradas, volviendo, en cierta medida, al estado de inseguridad generalizada de los primeros tiempo del capitalismo (Castel, 2003, 2009).

En el caso español la situación se complica dado que la crisis del petróleo coincide en el momento en que apenas se empezaba a vislumbrar un cambio político, y con éste, la capacidad de reformar el mercado de trabajo tras una larga dictadura que apenas dejó conocer aquí la estabilidad laboral, y vital, propia de los parámetros keynesianos (Babiano, 1993; Bilbao, 1993; Fina, 2001). En consecuencia, la seguridad y estabilidad han representado una breve experiencia en la vida de los trabajadores entrevistados estando la precariedad presente a lo largo de su vida, también en los más jóvenes, como experiencia personal y/o conociéndola a través de sus familiares, amigos y vecinos. Un hecho que ha dejado poso en sus conciencias facilitando la aceptación de pésimas condiciones laborales (Obiol, 2011). Aún así, sus derechos laborales y sociales han mejorado notablemente y esto ha significado, paradójicamente, un empeoramiento de su posición respecto el mercado de trabajo global que la liberalización comercial del sector ha puesto en evidencia. Un escenario previo complicado que la crisis del sector amplifica y que sustrae a los trabajadores, y a sus familias, de la capacidad de interpretar el presente y de planificar el futuro. En este sentido es necesario tener en cuenta la especificidad del mercado de trabajo valenciano, y con éste el de las comarcas analizadas: elevadas tasas de temporalidad -superando los niveles español y europeo-, donde los contratos fijos son concebidos como una concesión del empresariado, con un significativo volumen de trabajo parcial, niveles salariales bajos y una elevada siniestralidad laboral (Banyuls et al, 2005), además de un peso creciente en la estructura laboral y económica de la construcción que ha resultado ser perniciosa ante el carácter de la actual crisis económica. Hay que tener en cuenta que entre los años 1996 y 2008 el número de ocupados en la construcción se incrementó en un 152,3\% (elaboración propia, datos EPA). Una crisis que vino a empeorar la débil situación del sector del textil-confección tras la liberalización comercial que puede cuantificarse justo al inicio del proceso liberalizador en el cierre de 300 empresas -645 si ampliamos al periodo 2000-2008 (Directorio central de empresas, INE)- y la pérdida de 6.000 puestos de trabajo (CCOO, 2005). ${ }^{9}$

${ }^{9}$ La disponibilidad de datos sobre la desocupación del sector analizado desagregados a nivel comarcal es escasa. La información con la que contamos muestra que ya en el periodo 1999-2004 se dio un incremento del número de parados en el sector de un 10,11\% en el Comtat y un 114,5\% en La Vall d'Albaida. Sin embargo en l'Alcoià se dio un descenso del 14,87\% (elaboración propia a partir de datos del INEM). 
En cuanto a la familia, la diversificación en sus formas ha supuesto una ruptura con la hegemonía de la familia tradicional burguesa, caracterizada por una estricta diferenciación jerárquica por género y generación, construida sobre los cimientos de la distinción clara entre la esfera pública y la privada. Con su transformación las relaciones familiares han dejado de aportar respuestas dicotómicas a la ordenación de la vida cotidiana. Al contrario, presentan un amplio abanico de situaciones y formas que requieren de la negociación continua para ejercer sus roles. Se está desvaneciendo la certeza que suponía poder contar con unos parámetros culturales claros con los que interpretar el mundo y guiar el comportamiento cotidiano. Los individuos se ven forzados a dibujar sus propias sendas también en el ámbito más privado lo que supone el incremento de la sensación de incertidumbre, especialmente en nuestro país donde el bienestar depende de la existencia y perdurabilidad de vínculos familiares que proporcionen apoyo y atención. En definitiva, la familia se convierte también en una fuente de incertidumbre e inseguridad para los individuos, sobre todo en aquellas formas familiares que más se alejan del modelo tradicional.

Y también el Estado de bienestar funciona como fuente de incertidumbre. La confluencia del incremento de la percepción de los riesgos sociales junto al proceso de asistencialización y desmantelamiento del Estado de bienestar que se inició en la sociedad occidental en la década de los 70 , y que hoy se está profundizando, lo deja en una delicada coyuntura dificultando su función de amortiguar los riesgos sociales. En el caso español, además, hay que tener en cuenta la coincidencia de la construcción de una red básica de protección social a la ciudadanía a partir de la década de los 80 al tiempo que da comienzo la generalización de su cuestionamiento, una circunstancia que lo debilitaba desde sus inicios.

La cruzada en su contra se ha basado en la justificación de una intervención mínima y en su gestión privada, empresarial, a través de ahondar en los que son sus puntos más débiles: debilidad económica, formación de sentimientos anticompetitivos, burocratización excesiva, peligro de desequilibro demográfico financiero (Alonso, 2007:37). En consecuencia, poco a poco, ha ido perdiendo su capacidad desmercantilizadora a favor de la lógica remercantilizadora; se abstiene de su función en la administración de los riesgos (Ramos, 2006). Se trata de un proceso generalizado que en el caso valenciano resulta más agudo dada la gestión llevada a cabo por el Partido Popular en el gobierno autonómico desde 1995 que ha tenido como resultado su asistencialización, privatización y el fortalecimiento de pautas clientelares que han debilitado claramente su posición frente la ciudadanía (Azagra y Romero, 2007; Belis y Moreno, 2003; Felipe, 2007, 2008).

En definitiva, la combinación de mercado (de trabajo), familia -éstos dos ocupando una posición preferente- y Estado de bienestar construye un complejo mosaico de formas en el binomio certeza-incerteza, estrechamente relacionadas con las pautas culturales interiorizadas por los individuos que condicionan la percepción de la incertidumbre. Un binomio en el que destaca la ambivalencia de su percepción, inherente al mismo concepto según Ramos (2004). Ante esta incertidumbre la investigación realizada muestra cómo los trabajadores del textil-confección desarrollan mayoritariamente una serie de estrategias con el fin protegerse de la misma. 


\section{Los trabajadores del textil-confección ante la incertidumbre}

Con fines analíticos he identificado la incertidumbre como el cambio en las pautas culturales, como la imposibilidad de previsión acerca del día a día, como la falta de respuestas ya conocidas a los acontecimientos que se incorporan a la cotidianeidad. El estudio en el que se basa el artículo pone en evidencia que los trabajadores entrevistados buscan seguridad ante las transformaciones que están experimentando sus vidas a través de un, limitado dada su posición de clase, abanico de opciones entre las posibilidades que ofrecen la familia, el mercado, el Estado de bienestar y la comunidad, los cuales a la vez, a causa de los cambios que están también experimentando, incrementan su incertidumbre.

La investigación en la que se basa el artículo es fundamentalmente de carácter cualitativo con la realización de 42 entrevistas en profundidad a trabajadores en activo del sector del textil y la confección en diferentes municipios de las comarcas valencianas de l'Alcoià, el Comtat y la Vall d'Albaida en un momento de crisis económica, primero sectorial, después general. En la elección de estas comarcas como ámbito territorial de análisis pesó la importancia que el sector ha tenido históricamente llegando a impregnar la vida social de las comarcas en todas sus dimensiones (Aracil y Garcia Bonafé, 1974; Nebot et al, 1993; Pérez, 1997; Vallés, 1986). Por tanto cualquier cambio en el sector rebasa fácilmente las fronteras del ámbito laboral y económico.

La construcción de la muestra responde a un interés tipológico en el que convergen tanto los objetivos del estudio como el perfil sociodemográfico que de los trabajadores del sector se trazó a partir de la información aportada por el Censo de Población de 2001 (INE). Sus ejes vertebradores son: ${ }^{10}$

- El sexo, puesto que tanto la percepción de la incertidumbre (Lupton y Tulloch, 2002, 2003) como la posición ante el mercado de trabajo, el Estado de bienestar y la familia se ven condicionados de manera significativa por el género.

- La edad ha constituido también una variable esencial en el análisis por su influencia en las condiciones laborales y vitales, pero también por la intención de captar las diferencias existentes en la socialización de los entrevistados. El propósito fue poder valorar la incidencia de los acontecimientos vividos en la diferente percepción de la incertidumbre que los entrevistados pudieran manifestar así como en la orientación de sus estrategias de bienestar.

${ }^{10}$ Para conocer con mayor detalle la construcción de la muestra de investigación así como otras decisiones metodológicas se puede consultar la tesis doctoral completa en la plataforma virtual www.tdx.cat. 
Los grupos de edad configurados son tres: 16-29 años, 30-44 años y 45 años y más.

- El grado de estabilidad laboral, considerando estables a aquellos trabajadores con un contrato indefinido y sin perspectiva -al menos conocida- de cambios en su estatus laboral. Y como inestables a los trabajadores con contrato temporal, que trabajan en la economía sumergida o bien a los trabajadores que a pesar de contar con un contrato indefinido se encuentran afectados, en el momento de la entrevista, por una coyuntura complicada en la empresa en la que trabajan, por ejemplo en un expediente de regulación de empleo ${ }^{11}$.

- Y por último la zona de residencia, en la que he diferenciado entre aquellas poblaciones de las comarcas de mayor número de habitantes y con una larga tradición en el sector, es decir Alcoi y Ontinyent (Zona A); y pequeños municipios con significativas concentraciones de población ocupada en el sector analizado, como es el caso de Banyeres de Mariola donde un 7,3\% del total de ocupados en el sector de las comarcas se convierte en un 47,91\% respecto el total de ocupados del municipio (Zona B; elaboración propia con datos del Censo de Población de 2001).

Mi intención fue, además, que en la muestra estuvieran presentes otros elementos importantes desde un punto de vista teórico como la inmigración, la diversidad familiar, las diferentes trayectorias laborales, el distinto grado de implicación en el movimiento sindical, etc. Siempre con el mismo objetivo: lograr que la muestra reflejara la heterogeneidad de la realidad analizada al tiempo que aportara riqueza al análisis.

La realización de las entrevistas se concentró en los meses de abril y julio de 2005, cuando se daba por concluido el período de liberalización del comercio de productos textiles y de la confección, y los meses de abril y diciembre de 2008, en el preciso momento en que la crisis económica se generalizaba y se convertía en un constante elemento de debate mediático y político. El acceso a los entrevistados se consiguió a través de la colaboración con plataformas institucionales -en especial sindicatos- en combinación con la técnica de la bola de nieve. Salvo en el caso de los sindicatos, limité a dos el número de los contactos proporcionados con el fin de evitar una excesiva concentración en un mismo contexto. No podemos obviar, no obstante, la homogeneidad de la muestra que implica el hecho de centrar el análisis en un único sector profesional y en los trabajadores por cuenta ajena. De hecho, en la muestra únicamente hay tres personas que por nivel educativo y nivel de ingresos podríamos considerar que son de clase media -incluso en un caso, Carmen, media alta- el resto por sus características se encuadrarían en la clase trabajadora: trabaja-

${ }^{11}$ Me he centrado sólo en trabajadores por cuenta ajena, la gran mayoría de los empleados en la industria del textil y la confección, con cifras cercanas al $90 \%$ según el Censo de Población de 2001. 
dores manuales, con bajo nivel formativo, escasa cualificación laboral y unos ingresos económicos limitados. De todos modos, acercarme a la clase trabajadora ha sido un propósito declarado de la investigación. Buscaba de esta manera averiguar cómo responde la clase trabajadora a los retos de la nueva modernidad, ausente como está de las principales teorizaciones sobre la transformación social y cultural de la sociedad occidental en los últimos tiempos.

Como he señalado, el núcleo de este artículo no lo constituyen las estrategias basadas en los agentes de provisión de bienestar sino la actitud que las acompaña y que no deja de resultar una estrategia, esencial, para encarar la percepción de riesgo en su vida cotidiana. Mi propósito en este artículo es reflejar las respuestas que los trabajadores entrevistados dan al cambio, real o posible, y por tanto a la incertidumbre que les genera respecto sus condiciones vitales. De hecho, uno de los elementos claves respecto a la gestión de la incertidumbre que aparece en el análisis de los discursos de los entrevistados es el conjunto de normas que sobre su comportamiento comparten y que dicen aplicar en su vida cotidiana. Una situación que nos remite claramente al concepto de habitus de Bourdieu, a los referentes culturales que han ido construyendo generación tras generación procedentes de su posición de campo y que hoy conviven con aquellos rasgos constitutivos de lo que han llamado modernidad avanzada.

En este sentido se distinguen dos posturas básicas como respuesta al desconcierto generado por la transformación de los parámetros culturales que genera el actual proceso de modernización, así como la desazón que mayoritariamente les crea la situación crítica que atraviesa el sector del textil y la confección donde trabajan. Posturas que engloban, y sobre las que se construye, un complejo entramado de situaciones que vendrán muy marcadas por la posición que se ocupe en la estructura social así como por la trayectoria vital. Y son:

- En primer lugar el rechazo al cambio, entendido éste como elemento de introducción de incertidumbre, a causa del temor a que este cambio les suponga un empeoramiento de su situación vital.

- Y en segundo lugar, concebir el cambio como una oportunidad para su vida. Aquí se diferencian claramente dos perfiles: aquellos entrevistados que buscan activamente el cambio, y aquellos que esperan un cambio con la esperanza que tenga un impacto positivo en sus vidas.

\subsection{El temor al cambio}

El temor a un posible cambio se encuentra significativamente extendido entre los trabajadores que nutren la muestra de esta investigación, especialmente entre aquellos con una peor situación laboral y vital, es decir, aquellos trabajadores sin cualificación profesional, con pocas posibilidades de encontrar empleo fuera del sector 
analizado, de edad avanzada y con escaso acceso a la información. Conscientes de su posición de fragilidad, se consideran profundamente vulnerables frente a las decisiones de los empresarios, representantes de un mercado que no entienden y que los somete:

"Seguridad tengo la misma. Ninguna. La seguridad es que continuemos teniendo trabajo porque el empresario nos puede decir que tiene un compromiso con nosotros de hacer horas y mantenerlas, pero al final eso se va abajo.” Toni, 52 años. Estable. Zona A. ${ }^{12}$

Ante esta situación surge como principal reacción no pensar. Prefieren no detenerse a reflexionar en la coyuntura en la que viven y sus posibles consecuencias, una muestra clara de su precariedad, la cual "en convertir el futuro en algo incierto, impide cualquier previsión racional y en especial, aquel mínimo de fe y esperanza en el futuro que se precisa para rebelarse, sobre todo colectivamente, contra el presente, inclusive el más intolerable” (Bourdieu, 2000:121). El futuro se convierte para los entrevistados en algo lejano, intangible, difícilmente imaginable. Y conscientes de su falta de control sobre su devenir optan por no pensar en ello, centrándose en el presente o en su futuro más inmediato. No considero que se trate de indolencia, como se podría concluir de una lectura superficial de sus discursos, sino de una sensación más profunda y dolorosa: se encuentran totalmente desvalidos. Prefieren vivir al día, en el presente, conscientes de que no está en sus manos decidir las condiciones de su futuro y de que no les quedará más opción que asumir los hechos y situaciones que les sobrevengan.

"No me hago ilusiones, no tengo ideas respecto el futuro. Normalmente me gusta vivir al día. Vivo más el día a día que el futuro.” Mario, 20 años. Estable. Zona B.

"Pues preocuparme, me preocupa [su futuro] lo que pasa es que si me pongo a pensar tengo que dejarlo porque la verdad es que no me gusta el trabajo que hago y me gustaría encontrar una cosa que me gustara más. Pero claro, a veces da miedo planteárselo. Cuando empiezo a pensar lo tengo que dejar.” Luis, 29 años. Estable. Zona A.

No dibujan los caminos por donde transita su vida, lo saben, pero prefieren no pensarlo. Por ello focalizan su atención en su ámbito más próximo. Sus intereses y preocupaciones experimentan una privatización extrema y se plantean sólo expectativas a corto plazo. Una postura que les transmite una cierta sensación de control que les alivia de la angustia provocada por la inseguridad en la que viven.

“A mi me gusta tenerlo todo controlado, sí. A mi no me puedes decir a mediodía: ‘esta tarde nos vamos a Alacant”'. Chelo, 47 años. Inestable. Zona B.

${ }^{12}$ La lengua vehicular más frecuente en la realización de las entrevistas fue el catalán. Para facilitar la lectura del artículo he traducido directamente todas las citas incluidas. El nombre de los entrevistados es ficticio. 
"Yo soy dueña de mí y de mi casa, y de momento de mi hija que la puedo manejar como quiero. El día de mañana ya veremos. Pero de momento yo soy la que mando en mi casa y en mi familia.”Mónica, 40 años. Inestable. Zona A.

Y con idéntico propósito -tratar de ejercer el control sobre sus vidas- se imbuyen de una rígida y minuciosa planificación de su economía doméstica. Hasta el mínimo gasto es sopesado para valorar el alcance de la necesidad que viene a cubrir; la austeridad impregna por completo su día a día, y toda aquella actividad que pueda escaparse de esta austeridad es invadida por la planificación y la previsibilidad a través del ahorro tratando de minimizar su impacto sobre su, frágil, posición económica.

"Si no he tenido dinero no lo he hecho, las cosas se han hecho cuando se ha tenido dinero.”Manuel, 57 años. Inestable. Zona B.

"Yo miro el jornal que me entra al mes y empiezo: tanto, tanto, tanto... Este mes me hace falta esto pues este dinero lo reservo para eso, tanto para el préstamo... nos queda esto. Si la niña pide muchas cosas a última hora le digo 'hasta aquí, el resto al mes que viene'.” Carmina, 41 años. Inestable. Zona B.

"[su marido] tiene un archivo [...] Y cuando viene un recibo de luz dice: 'a ver qué pagamos’. Y miras a ver el año pasado por ahora qué pagábamos.” Lirios, 47 años.

Un ascetismo forzado por los bajos salarios del sector ${ }^{13}$ y que es vivido como un fracaso. La promesa fordista de poder acceder a un consumo estable y al acceso de bienes duraderos -que servía para obtener una mano de obra sumisa y disciplinadase ha desvanecido ante ellos sin apenas llegar a disfrutarla. Sin negar una considerable mejora en el acceso al consumo y en la calidad de vida respecto generaciones anteriores -tampoco muy complicado, teniendo en cuenta el bajo nivel del que se partía- la actitud que presentan una generación y otra, según sus palabras, es muy parecida: han de trabajar mucho y controlar mucho sus gastos, su vida en definitiva, para poder alcanzar una aceptable tranquilidad económica. Salvo una diferencia: la sensación de decepción de los entrevistados respecto a su nivel de vida se nos presenta como mayor que en las generaciones anteriores, no en vano las expectativas de consumo que han interiorizado son más elevadas. Estamos, como señala Young (2007:32) ante una sociedad bulímica donde la inclusión cultural es acompañada por una sistemática exclusión estructural.

Esta sociedad bulímica se les hace evidente día a día, sobre todo desde que la crisis económica general se solapó con la crisis del textil y la confección. Trabaja-

${ }^{13}$ Los datos referentes al coste salarial nos muestran un sector con sueldos inferiores a la media. En 2008 el coste salarial ordinario - pagos salariales de periodicidad mensual - en el textil era de 1.338,93€ y en la confección de 1.199,67€ mientras que el total de los sectores era de 1.548,32€ y en la industria de 1.723,07€ (INE, 2009; datos referidos al $4^{\circ}$ trimestre del año de referencia). 
dores que compraron nuevas viviendas, segundas residencias, automóviles, que se iban de vacaciones... hoy se están viendo ahogados por el nivel de endeudamiento que alcanzaron. No en vano, nos dicen los entrevistados, son gastos impropios de su clase. Se observa como el control social cae inmisericorde sobre aquellos que han pretendido asumir el nivel de vida de las clases medias y altas que por otro lado se ha convertido en transversal en la cultura occidental actual.

"La gente se ha trastornado ¿Coche? Un BMW. ¡Pero si es un trabajador como yo que tiene un chalet de 40 millones! ¿Cómo se compra un BMW? Es imposible que pueda mantenerlo, es imposible. Después te vas enterando: 'a fulanito le han embargado, no sé quien está a punto...'.” Eduardo, 36 años. Estable. Zona A.

En este sentido educan sus expectativas, no desean nada porque saben que difícilmente lo podrán conseguir. No pretenden, dicen, ser más de lo que son. Las necesidades que traslucen en sus discursos son muy básicas: sólo sueñan estar tranquilos.

"No soy una persona que me haya planteado el futuro: yo de mayor quiero ser eso, no. He ido día a día. [...] Me he preocupado siempre de no molestar a nadie y llevar mi marcha. Y ya está." Elena, 34 años. Inestable. Zona A.

En esta austeridad vital los vínculos familiares ocupan un lugar primordial. Es la familia la que provee de servicios de proximidad, la que palia las posibles consecuencias de los imprevistos económicos, la que contribuye, en la medida de sus posibilidades, a fortalecer la posición de los entrevistados en el mercado. Ante esta situación no es extraño que traten de fomentar y fortalecer estos vínculos. La sociabilidad de todos y cada uno de los trabajadores entrevistados descansa en la familia, entendida de manera más o menos extensa. El mismo hecho de constituir la fuente proveedora fundamental de servicios, muchos de éstos de una cotidianidad insoslayable, consolida esos vínculos. Pero no hacen falta excusas para verse, el hábito forma parte inherente de las relaciones familiares.

"Nosotros tenemos mucha vinculación, por necesidad.” Olga, 43 años. Inestable. Zona B.

“¿Si nos vemos? Nos vemos de normal todos los días.” Vicente, 40 años. Estable. Zona B.

Son relaciones favorecidas por su escasa movilidad geográfica así como por el reducido tamaño de las poblaciones en las que viven, y recaen sobre la capacidad de las mujeres para mantener el vínculo. Además, conscientes como son de su importancia, se esfuerzan en minimizar cualquier elemento que pueda generar un conflicto familiar.

"Bregas hay en todas las familias. Y a veces tienes que ponerte una venda en los ojos y como si no hubiera pasado."Carmina, 41 años. Inestable. Zona B.

"Yo es que le dije un día: 'bien aquí eres mi jefe, fuera serás mi primo hermano'. Sí porque no puedes mezclar faena con familia porque si no acabas mal.” Reme, 39 años. Estable. Zona A. 
A pesar de su empeño por controlar todos los aspectos de su vida cotidiana repetidamente se pone en evidencia el escaso margen de decisión con el que cuentan, también en las relaciones de pareja y familiares.

"¿Qué hago? ¿Buscarme alguien para que me haga compañía? Es que esas cosas no hay que forzarlas, esas cosas vienen.”Chelo, 47 años. Inestable. Zona B.

"Yo tengo padres, tú no puedes coger e irte por ahí. [...] Tú no haces tu vida, eso puedes hacerlo cuando no tienes familia, no tienes padres, que eres tú, entonces sí.” Carmina, 41 años. Inestable. Zona B.

Todas estas actitudes y toma de decisiones respecto su cotidianeidad convergen en una pretensión: evitar cualquier cambio en su posición actual. A pesar de la precariedad en la que viven prefieren mantenerse en ella que no iniciar un cambio que todavía pueda empeorar su situación. No en vano ya han experimentado los efectos negativos del cambio.

"El miedo, porque yo estuve mucho tiempo desocupado, o sea un contrato aquí un contrato allí y tengo ese miedo de volver otra vez a lo mismo. [...] Y aquí es más seguido, el jornal es más bajo también, pero es más seguido. Es más fastidioso también, pero no hay otra cosa, entonces aguantas.” Pepe, 43 años. Estable. Zona B.

"A mí me gustaría más tener una estabilidad porque los cambios... quien no los tiene dice 'jay qué bien un cambio!' Depende, porque yo llevo diez años con unos cambios en mi vida de lo peor, que digo yo. Horroroso, horroroso [...] De los cambios que he tenido no he tenido ningún favorable [...] Yo quiero una estabilidad. [...] tener una estabilidad es mucho.” Olga, 43 años. Inestable. Zona B.

De hecho incorporan este rechazo al cambio como una parte inherente, y valiosa, de su personalidad. Contradice pues el deseo del cambio por el cambio que se presenta como elemento definitorio de la identidad individual en la modernidad avanzada (Bauman 2005a; Béjar, 2007; Sennett, 2000, 2006).

"Y en las empresas que he estado, he estado bastante tiempo. No soy una persona que, como muchos, van probando.”Alfredo, 52 años. Estable. Zona A.

En conclusión, sus escasas posibilidades de elección dada su fragilidad estructural procedente de su clase social- les conduce a mostrar una marcada reticencia al cambio dada la incertidumbre que les provoca. Y desde esta constatación, y de manera totalmente complementaria a la estrategia de no reflexionar al respecto, despliegan la estrategia de la costumbre, de habituarse a la situación en la que se encuentran.

"Te acostumbras a la fuerza porque es la necesidad que tienes día a día, no hay más” Pepe, 43 años. Estable. Zona B.

Estas palabras nos remiten al concepto de "flexplotation” de Bourdieu (2000:12526), "un modo de dominación de nuevo cuño, basada en la institución de un estado generalizado y permanente de inseguridad que tiende a obligar a los trabajadores a la sumisión, a la aceptación de la explotación”. La actitud que mayoritariamente emerge de los discursos de los entrevistados respecto a la precariedad en la que 
trabajan y viven es su asunción como ineludible. No plantean cambios puesto que piensan que el cambio ni está en sus manos ni tiene por qué serles positivo. Se trata de la inoculación profunda de pautas de trabajo inciertas hasta el punto de que los explotados las conciben como un elemento natural e inherente del mismo régimen laboral. Y que en el caso de los trabajadores del sector se encuentra con un terreno perfectamente abonado. El estado de inseguridad que han observado en sus padres, amigos, vecinos y que también que muchos han sufrido en su propia trayectoria (Obiol, 2011), hace que los trabajadores no conciban nada más allá de la costumbre como estrategia válida de supervivencia. Y esta habituación los hace más frágiles y más fácilmente controlables por el capital.

"Y yo ahí de momento estoy bien. No es que esté contento, porque contento no está nadie de trabajar un fin de semana porque te obliguen, pero bien, te vas adaptando a ese sistema de trabajo y con el tiempo pues lo encuentras normal.” Alfredo, 52 años. Estable. Zona B.

Una gran parte de esta postura de conformidad procede de la asunción de que no pueden pedir más. Fácilmente, incluso en su entorno más inmediato, constatan que hay situaciones peores que la suya, tratan pues de proteger aquello que han conseguido. El temor de quedarse sin lo poco que tienen, sin lo que con gran esfuerzo han logrado, se hace muy agudo. Y este logro se basa simplemente en tener un empleo a pesar de que este empleo les genere cansancio, empeore su salud, les dificulte la sociabilidad con sus horarios... lo aceptan sin queja pues permite que tengan comida y casa, las que identifican como necesidades básicas. Es más, sancionan negativamente a aquellos que se quejan. Nos encontramos ante la máxima expresión de la precariedad: no se atreven a moverse no fueran a caer.

"Que yo siempre diré que hay casos peores. Nosotros, gracias a dios, tenemos comida, tenemos casa y no nos falta de nada.” Rebeca, 25 años. Estable. Zona B.

"Hombre lo primero es la comida, lo primero que nada es la comida y luego vestir y la marcha de una casa normal y corriente. Porque tampoco somos personas que hacemos demasiadas cosas fuera de lo normal.” Sofía, 47 años. Estable. Zona B.

En esta afirmación de Sofía se trasluce un propósito común entre los entrevistados: demostrar que su manera de encarar la situación en la que viven no tiene nada de extraordinario sino que es totalmente normal. El afán de normalidad y homogeneidad de los trabajadores entrevistados vuelve a contradecir la tendencia a mostrar una individualidad peculiar y diferente al grupo como valor preciado de esta época. Los protagonistas del estudio pretenden constantemente en sus discursos que sea consciente de su normalidad, de que no son más, ni sobre todo menos, que el resto de personas; que hacen lo que hacen porque es lo que hay que hacer, ni más ni menos. Se trata de una evidente mitificación de la rutina. Una rutina de la que huimos, o mejor, nos instan a huir (Sennett 2000, 2006) en este nuevo capitalismo, pero con la que ellos están cómodos y pretenden que continúe de la misma manera.

Este objetivo de formar parte de la mayoría se explica por el temor que manifiestan de salirse del grupo, no sólo por la seguridad que supone formar parte de un colectivo, cuyas normas sirven para explicarse un mundo cada vez menos claro, 
sino también porque saben que tienen más probabilidad de despuntar hacia abajo. Como bien nos señala Castel (1995) un imprevisto, una mala situación coyuntural puede comportar pasar de la posición de vulnerabilidad en la que se encuentran los trabajadores entrevistados a una situación de mayor vulnerabilidad social, e incluso exclusión social. Por tanto, no moverse significa para ellos tener una menor probabilidad de empeorar: si no caminan es imposible tropezar.

Los trabajadores se socializan en la precariedad y la conciben si no ya como un estado normal sí como un estado del que es imposible escapar. La fragmentación de su sujeto colectivo, la profunda individualización de sus relaciones laborales les supone esta actitud y los somete en mayor medida a una profunda incontrolabilidad de su presente y futuro. Sobre todo porque, como nos dice Young (2007:62) únicamente se percibe la injusticia si existe la expectativa de la equidad. Y esta expectativa que sí existía en época fordista -también en el fordismo español- se ha erosionado de manera evidente. Las aspiraciones son por tanto contenidas y las variaciones que se suceden en su vida cotidiana son engullidas por la práctica de la costumbre, sobre las que construyen de nuevo sus rutinas cotidianas pero también sus deseos, sus sueños...

"Si van viniendo cambios, pues vas aceptándolos, aceptándolos..." Inma, 40 años. Inestable. Zona B.

"Yo no lo pienso, pues mira, a la marcha. Cuando pasa algo pues pasa y ya está. Esto yo creo que es el día a día. Conforme van pasando cosas pues vas... superándolas. [...] Yo no pensaba nunca que podría pasar todo lo que he pasado.” Reme, 39 años. Estable. Zona A.

En definitiva, se trata de una clara actitud de negación del cambio ante la posibilidad de signifique un empeoramiento de su situación vital. Despliegan una doble estrategia adaptativa: evitan la reflexión sobre su situación -dada su constatación de que son incapaces de modificarla, incluso de interpretarla- y al mismo tiempo se empeñan en construir, y reconstruir, rutinas sobre elementos provisionales. Una actitud que en la muestra de trabajadores entrevistados convive con la concepción del cambio como oportunidad.

\subsection{El cambio como oportunidad}

Frente al hábito como estrategia, el cambio aparece también como oportunidad en los discursos de los entrevistados. Una oportunidad buscada por unos pocos, esperada por la mayoría según la posición que ocupen en la estructura social.

En la búsqueda activa del cambio se encuentran los pocos entrevistados que convergen con el perfil que se ha identificado como propio de la modernidad avanzada: flexible, mutable, ávido de cambio del cual son capaces de obtener resultados positivos. Y toman esta opción a pesar de que les obligue a replantearse los elementos de significado que han asumido como válidos hasta el momento, es decir, a pesar de que les genere incertidumbre. Se trata de una actitud claramente mediati- 
zada por la estructura social (Tulloch y Lupton, 2003), siendo la clase social identificada a través del nivel educativo y la cualificación laboral- y la edad las variables básicas en el caso que nos ocupa. En general, aquellos entrevistados que responden positivamente a los parámetros culturales hegemónicos son aquellos que estructuralmente se sienten más protegidos y por tanto se muestran más confiados en el futuro. No en vano, cuentan (por nivel formativo, por cualificación laboral, por edad) con más recursos para buscar un nuevo puesto de trabajo que es la principal vía de cambio en sus vidas que conciben. De hecho es Carmen, la entrevistada más cualificada formativa y laboralmente, que además no tiene responsabilidades familiares urgentes que atender, la que se ve más libre para aceptar el cambio, señalándolo incluso como un elemento esencial en su vida. Es Carmen quien presenta el perfil más adaptado a esta nueva individualidad que la modernización reflexiva nos dibuja.

"Pues yo ahora mismo sigo pensando que a mí el cambio me gusta, me gusta. De hecho en los trabajos en los que he estado han supuesto un cambio [...]. La monotonía ya me llegará cuando no tenga fuerzas. Ahora todavía tengo fuerzas para hacer cosas y enseñarme y ver cosas diferentes...” Carmen, 37 años. Estable. Zona A.

Las palabras de Carmen dejan entrever una atracción por el cambio muy importante poniendo en evidencia lo que nos señala Sennett (2000:84): "La inestabilidad misma de las organizaciones flexibles impone a los trabajadores la necesidad de 'cambiar de tiesto' es decir, de asumir riesgos en su trabajo. (...) el riesgo se vuelve algo normal y corriente.” Aún así, a pesar de poder permitirse esta situación por sus condiciones laborales, formativas, económicas y personales, hay ciertas resistencias al cambio que proceden de la familia y que Carmen identifica con el cuidado y la atención a su madre. Se trata de un elemento fundamental en la cosmovisión de los entrevistados que incluye a la fuerza un nuevo elemento en el debate sobre la sociedad contemporánea: la dimensión cultural y cómo ésta ha configurado -y se configura- en términos de consecución de bienestar.

No obstante, el ejemplo de Carmen es anecdótico puesto que la gran mayoría de los entrevistados aceptan sólo aquellos cambios que les supongan una mejora vital. Y lo hacen en muchas ocasiones de manera contradictoria respecto a otros momentos de su discurso en el que rechazan cualquier posibilidad de transformación. En este sentido, gran parte de los entrevistados se debaten entre la búsqueda de alternativas que mejoren sus condiciones de vida y encontrar el modo de protegerse ante posibles cambios que empeoren su día a día.

“¿Y te gusta que las cosas cambien? Si es para bien sí, si es para mal me preocupa.” María, 46 años. Estable. Zona A.

La posibilidad de que el cambio sea negativo les conduce al espejismo de que controlando todas y cada una de sus dimensiones el cambio podrá devenir positivo. Lamentablemente no cuentan con suficientes elementos de valoración de esta disyuntiva y terminan depositando sus anhelos en algo tan intangible y arbitrario como es la suerte, un hecho que no hace más que evidenciar su extrema fragilidad. 
Es importante señalar la introducción de diferencias de actitud ante el cambio según la edad. Entre los más jóvenes la esperanza de que les llegue un cambio y que sea positivo se encuentra más viva, les resulta más factible poder solucionar los motivos de su angustia. Se sienten aliviados por el simple hecho de constatar que aún pueden hacer planes de futuro en los que se incorpora la mejora de su situación laboral y con ésta su situación vital, que aún tienen tiempo.

"Si tuviera 30, te diría pues a lo mejor tengo una vida un poco... bastante mal, no. Pero como tengo 19 entonces creo que todavía queda vida.” Noelia, 19 años. Inestable. Zona A.

Sin embargo el peso de la experiencia de la precariedad que han visto muchos de ellos en sus familias les lleva a contemplar con temor el cambio y por tanto muestran una actitud de profunda responsabilidad y prudencia en sus actos y decisiones. El miedo forma parte de su experiencia cotidiana y si llevan a cabo alguna transformación de su entorno lo hacen de manera muy mesurada y planificada.

“¿Has pensado en buscarte otro trabajo? Pues a mí me gusta mucho la cocina, y quería hacer cocina. Lo que pasa es que, claro, quiero ver si esto se recupera... Si veo que la cosa va mal, pues como tengo los dos años del paro, quiero aprovechar [...] Ahora también estoy haciendo un curso de costura. Es un día a la semana... tres horitas... porque en cuestión de trajes de fiestas..., y la gente joven cada vez sabe coser menos.” Rebeca, 25 años. Estable. Zona B.

Por otro lado encontramos los trabajadores entrevistados de mayor edad que esperan con ansia un cambio previsible en su estatus laboral: la jubilación y con ésta la posibilidad de dejar atrás las constantes preocupaciones que les genera el trabajo remunerado.

"Yo mismo pienso: 'Pues bueno, si aguanta dos años, ya me meto en una edad que puedo jubilarme'. No es una jubilación al $100 \%$ de los sesenta y cinco años, pero bueno, ya puedes tener una jubilación. Y así estamos todos los que hay en la empresa”. Antonio, 57 años. Inestable. Zona B.

El análisis de los discursos de los trabajadores entrevistados constata que sus opciones de elección respecto a elementos que inciden en su contexto más cercano son muy limitadas y, no pocas veces, con consecuencias negativas para ellos. Un mercado de trabajo con la crisis del sector en primer término, agravada por la crisis económica general, una familia en transformación y un Estado de bienestar ausente (Obiol, 2010), conducen a los trabajadores a sentirse desamparados y obligados a confiar únicamente en sus propios recursos para proveerse de bienestar cotidiano. Ante esta situación se abandonan al destino pues, como señala Elena (34 años, inestable, zona B), "Lo que tenga que pasar, pasará".

\section{La incertidumbre como elemento de dominación}


La situación que atraviesan los trabajadores del textil y la confección en las comarcas de l'Alcoià, el Comtat y la Vall d'Albaida es una clara muestra de los efectos, la mayoría dolorosos, de la inmersión en un estado continuo de incertidumbre. A pesar de que para una gran parte de los trabajadores entrevistados la relación con la seguridad procedente del mercado de trabajo ha sido más bien exigua, dada la histórica precariedad de las condiciones laborales del sector analizado, hoy la incertidumbre adquiere nuevos contornos y, por tanto, consecuencias. Por un lado porque alcanza a esferas que hasta el momento parecían encontrarse a salvo, es el caso de la familia que a pesar de mantenerse para los trabajadores entrevistados como fuente esencial de cobijo y apoyo está experimentado profundas transformaciones que, cuando menos, varía los modos en su función de provisión de bienestar. Por otro lado, porque la liberalización comercial del textil y la confección, detonante de la crisis que sufren, cuestiona su hasta el momento posición preferente en el mercado global como mano de obra barata. En definitiva, la principal novedad de la percepción de incertidumbre de los trabajadores del textil-confección de las comarcas analizadas radica en la desposesión de la capacidad para otorgar significado a la situación por la que transitan. Los discursos de los trabajadores entrevistados están impregnados de una angustiante inquietud al verse obligados a enfrentarse a una situación que no responde a los códigos interpretativos con los que se socializaron y que hasta ahora les había sido útiles para guiar y ordenar cognitivamente su mundo, sin tener preparados otros.

El objetivo de este artículo ha sido reflejar la actitud de los trabajadores de un sector en plena crisis ante la incertidumbre, teniendo en cuenta que se trata del más básico de los recursos con los que cuentan. En este sentido, la respuesta mayoritaria ha sido la construcción de una barrera defensiva ante cualquier elemento que pueda introducir en sus vidas incertidumbre, o bien agravar la ya existente siendo la edad y el nivel educativo (y con éste la cualificación laboral) variables que matizan la consideración de la incerteza. El nivel educativo porque les ofrece un asidero ante la posibilidad que más temen: quedarse sin empleo. Aquellos entrevistados -pocosque cuentan con estudios superiores se autoperciben con mayores oportunidades para poder enderezar su vida profesional si finalmente se les expulsa del sector analizado. Esta percepción contribuye a que la inquietud ante su futuro remita, aunque sea levemente. En segundo lugar, la edad, más bien el momento en el ciclo vital en el que se encuentren, puede cambiar sustancialmente la percepción de la situación en la que viven, siendo los trabajadores de edades comprendidas, aproximadamente, entre los 40 y 50 años los que se sienten más desamparados y así lo manifiestan: son demasiado mayores para cambiar el rumbo de sus trayectorias laborales y demasiado jóvenes para esperar con calma la jubilación. Ambas fuentes de alivio les son negadas y eso les genera una elevada desazón.

No obstante son variables que modulan la percepción de la incerteza pero no la anulan. Prácticamente la totalidad de trabajadores entrevistados consideran de manera negativa la incertidumbre que genera la situación del sector en el que trabajan junto a las transformaciones que experimentan la familia y el Estado de bienestar. No es de extrañar que se entreguen absolutamente al destino, que dejen senci- 
llamente pasar el tiempo centrándose en conseguir dominar la esfera privada y asumiendo, mejor si es poco a poco, los cambios que se suceden en su día a día a base de costumbre y con los limitados recursos que tienen a su alcance. En este sentido sus únicas herramientas son poner límite a sus intereses y expectativas, sumergirse en una actitud de austeridad vital, a la vez que tratan de construir una cierta regularidad, el hábito, sobre la imprevisibilidad que caracteriza hoy no sólo el mercado de trabajo sino todas las esferas de su vida cotidiana.

Conscientes de que la sensación de seguridad escasea y que no es perdurable en el tiempo, se dedican a buscar breves cápsulas de seguridad en un contexto donde domina el miedo. Los entrevistados se limitan, como dicen, a ir asumiendo y tratando de neutralizar los hechos que muchas veces pueden trastornar su precario equilibrio. Temen el cambio porque lo conocen; lo han experimentado demasiadas veces, y con frecuencia de manera repentina, afectando negativamente a sus condiciones de vida. Tan sólo desean poder tener tiempo para asumirlo. Se entregan al hábito de tejer sin fin frágiles telas de seguridad, destejiendo y volviendo a tejer cuando un imprevisto les destroza los hilos sobre los que habían conseguido levantar su cotidianidad e incluso un esbozo de futuro. Y esto dificulta y mucho cualquier intento de construcción de alternativas de acción de carácter colectivo, a medio o largo plazo. La incertidumbre juega aquí un papel fundamental como fuente de sumisión y dominación, debilitando enormemente la posición de campo de estos trabajadores lo que a la vez impregna su habitus de temor y desprotección. Hacer y deshacer, esa es la actividad a la que se dedican rutinariamente y sin descanso, esperando que lleguen, si es que llegan, tiempos mejores.

\section{Bibliografía}


Adams, J. (1995). Risk. London: UCL Press.

Adelantado, J; Noguera, J.A.; Rambla, X. (2000). "El marco de análisis: las relaciones complejas entre estructura social y políticas sociales” en Adelantado, J. (coord.) Cambios en el Estado del Bienestar. Políticas sociales y desigualdades en España. Barcelona: Icaria. pp. 23-62.

Alonso, L.E. (2007). La crisis de la ciudadanía laboral. Barcelona: Anthropos.

Aracil, R.; Garcia Bonafé, M. (1974). Industrialització al País Valencià: Alcoi. València: Ed. Eliseu Climent.

Azagra, J.; Romero, J. (2007). País complex. Canvi social i polítiques públiques en la societat valenciana, 1977-2006. València: Publicacions de la Universitat de València.

Babiano, J. (1993). "Las peculiaridades del fordismo español" Cuaderno de Rela$\begin{array}{llll}\text { ciones } & \text { Laborales, } & \text { 77-94. }\end{array}$ http://www.ucm.es/info/femp/cuadernos/cuadernos.htm

Banyuls, J.; Cano, E.; Pitxer, J.V.; Sánchez, A. (2005). Economia laboral i polítiques d'ocupació. València: Publicacions de la Universitat de València.

Bauman, Z. (2001). Community. Seeking Safety in an Insecure World. Cambridge: Polity Press.

- (2003). "Individualmente, pero juntos. Prefacio" en Beck, U.; Beck-Gernsheim, E. La individualización. Barcelona: Paidós. pp. 19-26.

- (2005a). Identitat. Converses amb Benedetto Vecchi. València: Universitat de València.

- (2005b). Vidas desperdiciadas. La modernidad y sus parias. Barcelona: Paidós.

- (2005c). Amor líquido. Acerca de la fragilidad de los vínculos humanos. México:

Fondo de Cultura Económica.

- (2006). Vida líquida. Barcelona: Paidós.

- (2007a). Liquid Times. Living in an Age of Uncertainty. Cambridge: Polity Press.

- (2007b). La sociedad individualizada. Madrid: Cátedra.

Beck, U. (1996). "Risk Society and the Provident State” en Lash, S.; Szerszynski,

B.; Wynne, B. (eds.) Risk, Environment and Modernity. Towards a New Ecology.

London, Thousand Oaks, New Delhi: Sage. pp. 27-43.

- (1998). La sociedad del riesgo. Hacia una nueva modernidad. Barcelona: Paidós.

- (2000). Un nuevo mundo feliz. La precariedad del trabajo en la era de la globalización. Barcelona: Paidós

- (2002). La sociedad del riesgo global. Madrid:Siglo XXI.

- (2008). La sociedad del riesgo mundial. En busca de la seguridad perdida. Barcelona: Paidós.

Beck, U.; Beck-Gernsheim, E. (2001). El normal caos del amor. Las nuevas formas de la relación amorosa. Barcelona: Paidós.

- (2003). La individualización. El individualismo institucionalizado y sus consecuencias sociales y políticas. Barcelona: Paidós.

- (2008). Generación global. Barcelona: Paidós.

Beck, U.; Giddens, A.; Lash, S. (1994). Reflexive Modernization. Politics, Tradition and Aesthetics in the modern social order. Cambridge: Polity Press. 
Beck-Gernsheim, E. (2003). La reinvención de la familia. En busca de nuevas formas de convivencia. Barcelona: Paidós.

Belis, V.; Moreno, A. (2002). "Evolución del sistema de servicios sociales en la Comunidad Valenciana” Arxius de Ciències Socials, $7 . \quad$ pp. 9-24. http://www.uv.es/ sociolog/arxius/

Bilbao, A. (1993). Obreros y ciudadanos. La desestructuración de la clase obrera. Madrid: Ed. Trotta.

Béjar, H. (2007). Identitades inciertas: Zygmunt Bauman. Barcelona:Herder.

Blossfeld, H.P.; Klijzing, E.; Mills, M.; Kurz, K. (eds.) (2005). Globalization, Uncertainty and Youth in Society. London, New York: Routledge.

Blossfeld, H.; Buchholz, S.; Hofacker, D. (eds.) (2006). Globalization, uncertainty and late careers in society. London, New York: Routledge.

Blossfeld, H.; Hofmeister, H. (eds.) (2008). Globalization, uncertainty and women's careers: an international comparison. Cheltenham: Edward Elgar.

Blossfeld, H; Mills, M; Bernardi, F. (eds.) (2008). Globalization, uncertainty, and men's careers: an international comparison. Cheltenham: Edward Elgar.

Cano, Ernest (2000). “Análisis de los procesos socioeconómicos de precarización laboral” en Cano, E.; Bilbao, A.; Standing, G. (ed.) Precariedad laboral, flexibilidad y desregulación. València: Germania. pp. 25-68.

- (2007). "La extensión de la precariedad laboral como norma social" Sociedad y Utopía. Revista de Ciencias Sociales, $29 . \quad$ pp. 117-137. http://www.sociedadyutopia.es/

Bourdieu, P. (2000) Contrafuegos: reflexiones para servir a la resistencia contra la invasión neoliberal. Barcelona: Anagrama.

- (2003). Las estructuras sociales de la economía. Barcelona: Anagrama.

Bourdieu, P.; Wacquant, L. (1994). Per a una sociologia reflexiva. Barcelona: Herder.

Castel, R. (1995). Les métamorphoses de la question sociale. Une chronique du salariat. París: Fayard.

- (2003). L'insecurité sociale. Qu'est-ce qu'être protégé? Paris: La Republique des idees. Seuil.

- (2009). La montée des incertitudes. Travail, protections, status de l'individu. Paris: Seuil.

Comissions Obreres-CCOO (2005). Orientación profesional dirigida a trabajadores y trabajadoras en activo en los sectores del textil y la confección del ATLAS. Análisis socioeconómico del sector textil en el País Valenciano http://www.forempv.ccoo.es/proyectos/atlas/seccion.asp?p=seccion_v\&id=180.

Douglas, M.(1992). Risk and Blame. Essays in cultural theory. London, New York: Routledge.

Douglas, M.; Wildavsky, A. (1983). Risk and Culture. An Essay on the Selection of Technological and Environmental Dangers. Berkeley: University of California Press.

Ferrera, M. (1995). "Los Estados del Bienestar del Sur en la Europa Social” en Sarasa, S. y Moreno, L. El Estado del Bienestar en la Europa del Sur, vol 7. 
Madrid: Consejo Superior de Investigaciones Científicas/Instituto de Estudios Sociales Avanzados. pp. 85-111.

- (1996).“The 'Southern Model' of Welfare in Social Europe”. Journal of European Social Policy, 6. pp. 1737. doi: 10.1177/095892879600600102; http://esp.sagepub.com/

Elliot, A. (2002). "Beck's Sociology of Risk: A Critical Assessment” Sociology, vol. 36(2). $\quad$ pp. 293-315. doi: 10.1177/0038038502036002004 http://soc.sagepub.com/

Esping-Andersen, G. (2000). Fundamentos sociales de las economías postindustriales. Barcelona: Ariel.

Felipe, M.J. (2007). "El sistema de protección social en la Comunidad Valenciana: algunos indicadores sociales" Arxius de Ciències Socials, 17. pp. 43-53. http://www.uv.es/ sociolog/arxius/

- (2008). "El sistema de protección social en la Comunidad Valenciana" Quaderns de Ciències Socials, 9. Segona època.

Fina, L. (2001). El reto del empleo. Madrid: McGrawhill.

Gardberg Morner, C. (2000). "Making Ends Meet. Lone Mothers' Local Subsistence Strategies. Case Studies from Italy and Sweden" Mannheimer Zentrum für Europäische Sozialforschung. Working paper núm. 13. http://www.mzes.unimannheim.de

Giddens, A. (1991). Modernity and Self-identity. Self and Society in the Late Modern Age. Cambridge: Polity Press

- (1995). La transformación de la intimidad. Sexualidad, amor y erotismo en las sociedades modernas. Madrid: Cátedra.

- (2000). Un mundo desbocado. Los efectos de la globalización en nuestras vidas. Madrid: Taurus.

Luhmann, N. (1998). Sociología del riesgo. México: Universidad Iberoamericana. Triana Editores.

Lupton, D. (1999). Risk. London: Routledge.

Lupton, D.; Tulloch, J. (2002). '"Risk is Part of Your Life': Risk Epistemologies among a Group of Australians" Sociology, vol.36 (2). pp. 317334. doi:10.1177/0038038502036002005

Mingione, E. (2000). "Modello sud europeo di Welfare, forme di povertà e politiche contro l'esclusione sociale.” Sociologia e polítiche sociali, 1, 3er any. pp. 87112.

Montagut, T. (2000). Política social: una introducción. Barcelona: Ariel.

Mythen, G. (2005). "Employment, individualization and insecurity: rethinking the risk society perspective" The Sociological Review, vol. 53. pp. 129-149. DOI: 10.1111/j.1467-954X.2005.00506.x http://onlinelibrary.wiley.com/

Naldini, M. (2003). The family in the Mediteranean welfare states. London: Frank Cass.

Nebot, J.R.; Torró, J.; Masanet, C.M.; Martínez, A. (1993). L’Alcoià i el Comtat. Guia natural, històrica i cultural. Alcoi: Gráficas Alcoy. 
Obiol, S. (2010). “La paradoxal relació dels treballadors amb l'Estat de benestar: una primera aproximació” Quaderns d'educació contínua, 22. pp. 31-39.

- (2011). "Competir por la precariedad. Consecuencias en las condiciones laborales del sector textil y la confección tras su liberalización comercial.” Sociología del Trabajo, 71. pp. 45-62

Pahl, R.E. (1984). Divisions of labour. Oxford: Basil Blackwell.

Pahl, R.E.; Wallace, C. (1985). "Household Work Strategies in Economic Recession" a Redclift y Mingione, E. (ed.) Beyond the employment. Household, Gender and Subsistence. Oxford: Basil Blackwell.pp.189-227.

Portes, A. (1998). "Social Capital: Its Origins and Applications in Modern Sociology" Annual Review Sociology, vol. 24. pp. 1-24. DOI: 10.1146/annurev.soc.24.1.1 http://www.annualreviews.org/journal/soc

- (2000). "Two Meanings of Social Capital" Sociological Forum, vol 15(1). pp. 112.

Pérez, D. (1997). Reestructuració dels espais industrials de l'eix Alcoi-CocentainaMuro. Alacant: Institut de Cultura Joan Gil Albert.

Prieto, C. (2002). "La degradación del empleo o la norma social del empleo flexibilizado” Sistema, 168-169. pp. 89-106. http://www.fundacionsistema.com/

Ramos, R. (2004). "De la sociedad del riesgo a la sociedad de la incertidumbre" en Luján, J.L. y Echevarría, J. (eds.) Gobernar los riesgos. Ciencia y valores en la sociedad del riesgo. Madrid: Biblioteca Nueva. pp. 35-50.

- (2006). "La deriva hacia la incertidumbre de la sociedad del riesgo" en Ruano Gómez, J.D. (coord.) I Jornadas sobre Gestión de Crisis: más allá de la sociedad del riesgo. Facultad de Sociología de la Universidad de A Coruña 9 y 10 de noviembre de 2005. pp. 27-44.

Saraceno, C. (1995). "Familismo ambivalente y clientelismo categórico en el Estado de Bienestar italiano" en Sarasa, S.; Moreno, L. (comp.) El Estado del Bienestar en la Europa del Sur. vol 7. Madrid: CSIC. pp. 261-88.

Sebastià, M. (2005). "El sector textil de la UEM ante la eliminación de contingentes en el comercio exterior" Boletín económico del Banco de España. Madrid: Banco de España. pp. 75-81. http://www.bde.es

Sennett, R. (2000). La corrosión del carácter. Las consecuencias personales del trabajo en el nuevo capitalismo. Barcelona: Anagrama.

- (2006). The Culture of the New Capitalism. New Haven\&London: Yale University Press.

Smith, D.; Macnicol, J. (2001). "Social insecurity and the informal economy. Survival strategies on a South London estate" en Edwards, R.; Glover, J. (ed.) Risk and Citizenship. Key Issues in Welfare. London, New York: Routledge. pp. 142156.

Tobio, C. (2005). Madres que trabajan. Dilemas y estrategias. Madrid: Cátedra.

Trifiletti, Rossana (1999). "Southern European Welfare Regimes and the Worsening Position of Women" Journal of European Social Policy, vol.9 (1) London: SAGE. pp. 49-64. doi: 10.1177/095892879900900103 http://esp.sagepub.com/ 
Tulloch, J; Lupton, D. (2003). Risk and Everyday Life. London, Thousand Oaks, New Delhi: Sage.

VALLÉS, I. (1986). INDÚSTRIA TÈXTIL I SOCIETAT A LA REGIÓ ALCOI-ONTINYENT 17801930. VALÈNCIA: UNIVERSITAT DE VALÈNCIA, INSTITUT VALENCIÀ D’ESTUDIS I INVESTIGACIÓ.

Vogel, L. (1995). "El descubrimiento del síndrome Ardystil: discurso médico y relaciones entre precarización y salud” Sociología del Trabajo, 23. pp. 11-127.

Young, J. (2007). The Vertigo of Late Modernity. London, Thousand Oaks, New Delhi: Sage. 